\title{
Efeito antinociceptivo da própolis oriunda de duas vegetações distintas
}

\section{Antinociceptive effect of propolis from two different vegetations}

\author{
Emanuelle Karine Frota Batista ${ }^{1}$; Hebelys Ibiapina da Trindade ${ }^{2}$; Maria do Carmo \\ de Souza Batista ${ }^{3}$
}

\begin{abstract}
Resumo
O objetivo deste trabalho foi avaliar o efeito antinociceptivo da própolis, comparando soluções elaboradas a partir da própolis obtida do apiário do Centro de Ciências Agrárias (CCA) da Universidade Federal do Piauí, com o extrato oriundo do Laboratório Apis Flora. Foram utilizados 48 camundongos, divididos em seis grupos que foram tratados com solução hidroetanólica (veículo, $20 \mathrm{~mL} / \mathrm{Kg}$, v.o.), dipirona (controle positivo, $50 \mathrm{~mL} / \mathrm{Kg}$, v.o.), solução de própolis a $10 \%$ (obtida do CCA e Apis Flora, $20 \mathrm{~mL} / \mathrm{Kg}$, v.o.) e solução de própolis a $20 \%$ (obtida do CCA e Apis Flora, $20 \mathrm{~mL} / \mathrm{Kg}$, v.o.). O estimulo nociceptivo foi induzido por meio da administração intraperitoneal (i.p.) de ácido acético a $0,6 \%, 20$ minutos após a administração de cada tratamento. Realizou-se a contagem do numero de contorções abdominais por um período de 20 minutos, e calculou-se o percentual de inibição da sensação dolorosa proporcionado por cada tratamento. Os resultados mostraram que o grupo controle, tratados com solução hidroetanólica, diferiu significativamente de todos os demais, e que os tratados com a solução de própolis a $10 \%$ e $20 \%$, de ambas as origens, não diferem significativamente entre si e nem do controle positivo, demonstrando possuir efeito antinociceptivo semelhante.
\end{abstract}

Palavras-chave: Dor. Própolis. Antinocicepção.

\begin{abstract}
The aim of this study was to evaluate the analgesic effect of propolis, comparing solutions prepared from propolis obtained from the apiary of the Centre for Agricultural Sciences (CCA) of the Federal University of Piauí, with the extract from the Apis Flora Laboratory. Forty eight mice were divided into six groups treated with hydroethanol solution (vehicle, $20 \mathrm{~mL} / \mathrm{Kg}$, p.o.), dipyrone (positive control, $50 \mathrm{~mL} / \mathrm{Kg}$, p.o.), propolis solution $10 \%$ (obtained from CCA and Apis Flora, $20 \mathrm{~mL} / \mathrm{Kg}$, p.o.) and propolis $20 \%$ solution (obtained from CCA and Apis Flora, $20 \mathrm{~mL} / \mathrm{Kg}$, p.o.). The nociceptive stimulus was induced by intraperitoneal (i.p.) administration of $0.6 \%$ acetic acid 20 minutes after administration of each treatment. The number of writhing was performed, for a period of 20 minutes, and the inhibition percentage of the painful sensation provided by each treatment were calculated. The results showed that the control group, treated with hydroethanol solution, was significantly different from all others, and those treated with propolis solution at $10 \%$ and $20 \%$ from, both sources do not differ significantly from each other and not the positive control, showing similar analgesic effect.
\end{abstract}

Keywods: Pain. Propolis. Antinociception.

\footnotetext{
${ }^{1}$ Médica veterinária. Mestre em Ciência animal pela Universidade Federal do Piauí. E-mail: emanuellefrota@yahoo.com.br

${ }^{2}$ Médica veterinária. Doutora em Ciência animal pelo Instituto Federal do Maranhão - São Raimundo das Mangabeiras. E-mail: hebelys@yahoo.com.br

${ }^{3}$ Médica veterinária. Doutora em Ciência veterinária pela Universidade Federal do Piauí. E-mail: mcbatista@ufpi.edu.br
} 


\section{Introdução}

A busca de novas substâncias analgésicas derivadas de produtos naturais tem crescido nos últimos anos, objetivando encontrar novas substâncias que apresentem boa potência e poucos efeitos adversos, proporcionando nova possibilidade de tratamento terapêutico para quadros dolorosos (SIMÕES, 2007).

Os produtos naturais constituem importante fonte de pesquisa visando à descoberta de novas substâncias com atividades farmacológicas. Nos últimos anos tem crescido o uso de produtos naturais nas práticas de saúde, como alternativas terapêuticas mais baratas e relativamente seguras (OLIVEIRA et al., 2005; PASSOS et al., 2009). Entre estes produtos, a própolis apresenta grande aceitação devido a suas propriedades terapêuticas (BARBOSA et al., 2009). A própolis é uma resina de coloração e consistência variada, coletada por abelhas (Apis melifera) de diversas partes das plantas, como gemas vegetativas, botões florais e exsudados resinosos, acrescidas de secreções salivares, ceras e pólen (CASTRO et al., 2007; SILVA et al., 2005).

Desde a antiguidade, a própolis é utilizada no tratamento de diversas enfermidades, sendo atualmente um dos produtos naturais de maior destaque, por conta das diversas propriedades biológicas que possui, sendo utilizada como antimicrobiano (antibacteriano e antiviral), antioxidante, anti-inflamatório, imunomodulador, hipotensor, cicatrizante, anestésico, anticancerígeno, e anticariogênico. Essas propriedades estão relacionadas com sua composição química, pois é composto por flavonoides, ácidos aromáticos e ésteres, aldeídos e cetonas, terpenoides e fenilpropanoides, esteroides, aminoácidos, polissacarídeos, hidrocarbonetos, ácidos graxos e vários outros compostos em menores quantidades (BARBOSA et al., 2009; LUSTOSA et al., 2008). A proporção dessas substâncias varia e depende do local e da época da coleta (SILVA et al., 2005).
Os flavonoides são considerados os principais constituintes encontrados na própolis com atividade farmacológica (MENEZES, 2005). São definidos como compostos fenólicos provenientes de plantas, que agem em diferentes processos fisiológicos, interferindo com a absorção de ferro, atuando na ação e absorção de vitaminas, nos processos de cicatrização, como antioxidantes e exercendo função antimicrobiana e moduladora do sistema imune e que também apresentam ação anti-inflamatória, analgésica, regenerativa de cartilagens, ossos e produzem vasodilatação (BARBOSA et al., 2009; CHEN; ZHANG; XIE, 2005; FERNANDES JUNIOR et al., 2006; MENEZES, 2005).

A própolis é bastante utilizada na medicina popular brasileira e comercializada na forma de suspensões, extratos, comprimidos, pós, cremes para o tratamento de feridas e, sobretudo, em produtos de beleza. Um dos maiores problemas na utilização terapêutica da própolis é a variação da sua composição, que depende da flora, mudanças sazonais em determinada região geográfica, tempo de colheita e presença de contaminantes (DULCETTI JUNIOR et al., 2004).

Estas variáveis acarretam mudanças em suas propriedades farmacológicas, que tendem a serem maiores em regiões tropicais que em temperadas, devido à riqueza vegetal existente. A época da coleta é outro fator importante na determinação da composição química da própolis, pois em países como o Brasil, a coleta ocorre o ano todo, gerando possíveis variáveis sazonais, que acabam por interferir na sua eficácia terapêutica (BARBOSA et al., 2009; TRUSHEVA et al., 2006).

Embora já tenham sido comprovadas inúmeras das propriedades terapêuticas da própolis, pouco se sabe sobre sua atividade antinociceptiva. E como o estado do Piauí apresenta potencial apícola expressivo, surgiu o interesse em estudar a ação antinociceptiva da própolis piauiense (SILVA et al., 2005). Portanto, este trabalho 
foi realizado com o objetivo de avaliar o efeito antinociceptivo da própolis proveniente do apiário do Departamento de Zootecnia do Centro de Ciências Agrárias (CCA) da Universidade Federal do Piauí (UFPI), bem como comparar esse efeito com outras soluções de própolis oriundas do sudeste do Brasil (Apis Flora).

\section{Material e Métodos}

\section{Animais}

Foram utilizados 48 camundongos (Mus musculus) de ambos os sexos, com idade entre três e quatro meses e peso entre 20 e 30 gramas, distribuídos em seis grupos (metade de cada sexo), e mantidos em condições controladas de temperatura $\left(25 \pm 2{ }^{\circ} \mathrm{C}\right)$ e ciclo de claro/escuro de $12 \mathrm{~h}$, com livre acesso a água e ração. Os animais foram obtidos do Biotério de Manutenção de Animais Destinados à Experimentação (BIOMADEX) do Centro de Ciências Agrárias da Universidade Federal do Piauí. O projeto foi avaliado e aprovado pelo Comitê de Ética em Experimentação com Animais da Universidade Federal do Piauí (UFPI), protocolo n ${ }^{\circ}$ 095/2010.

\section{Local do experimento}

O experimento foi conduzido no Laboratório de Ciências Fisiológicas do Departamento de Morfofisiologia Veterinária do Centro de Ciências Agrárias da Universidade Federal do Piauí.

\section{Própolis utilizada}

Utilizaram-se própolis de duas origens distintas, a primeira foi cedida pela empresa Apis
Flora Industrial e Comercial LTDA, localizada em Ribeirão Preto-SP. E a segunda foi obtida de colmeias do setor de apicultura do Departamento de Zootecnia no Centro de Ciências Agrárias, UFPI.

\section{Preparação do extrato}

As soluções de própolis a $10 \%$ e $20 \%$ Apis Flora foram preparadas a partir da tintura produzida pelo Laboratório Apis flora, usando-se como diluente a água destilada.

Quanto à própolis do CCA, fizeram-se inicialmente as raspagens de colmeias e preparouse a tintura conforme a técnica de Bianchi (1991) e a partir dela, as soluções aquosas a $10 \%$ e $20 \%$ em água destilada.

\section{Avaliação da atividade antinociceptiva}

Utilizou-se o teste de contorções abdominais em camundongos, realizado de acordo com Koster, Anderson e Beer (1959). Para a indução do estimulo nociceptivo foi administrado o ácido acético a $0,6 \%(0,1 \mathrm{~N})$ intraperitonealmente (i.p.) em cada animal, na proporção de $10 \mathrm{~mL} / \mathrm{Kg}, 20$ minutos após a administração de cada tratamento (SUDO et al., 2010), conforme tabela 1 . Imediatamente após a aplicação do acido acético, cada animal foi colocado em caixa plástica e iniciada a contagem do numero de contorções abdominais por um período de 20 minutos. Ao final, foi feito o cálculo do percentual de inibição de sensação dolorosa. A substância padrão utilizada como controle positivo foi a dipirona $(50 \mathrm{~mL} / \mathrm{Kg})$, por possuir atividade analgésica cientificamente comprovada e largo uso em clínica médica e em experimentação animal (IMAGAWA, 2006). 
Tabela 1 - Delineamento experimental para determinação do percentual de inibição de contorções abdominais induzidas pelo acido acético em camundongos, após administração oral da solução de própolis a 10\% e 20\%, obtida da Apis Flora e Centro de Ciências Agrárias - UFPI

\begin{tabular}{l|lcc}
\hline GRUPO & TRATAMENTO & POSOLOGIA (ml/kg) & VIA \\
\hline G1 (controle) & Solução hidroalcoólica + ác. acético & 20 & Oral \\
G2 (padrão) & Dipirona + ác. acético & 50 & Oral \\
G3 (teste) & Solução própolis 10\% (Apis Flora) + ác. acético & 20 & Oral \\
G4 (teste) & Solução própolis 10\% (CCA) +ác. Acético & 20 & Oral \\
G5 (teste) & Solução própolis 20\% (Apis Flora) + ác. acético & 20 & Oral \\
G6 (teste) & Solução própolis 20\% (CCA) + ác. acético & 20 & Oral \\
\hline
\end{tabular}

Fonte: Autores.

\section{Analise estatística}

Os dados obtidos foram submetidos à análise de variância ANOVA seguida pelo pós-teste de Tukey. $\mathrm{P}<0,05$ foi considerado como significante.

\section{Resultados e Discussão}

Houve, em todos os grupos, manifestação de dor após a administração i.p. de ácido acético a $0,6 \%$. O ácido acético induz contorções abdominais por meio da liberação de mediadores endógenos, que estimulam os neurônios nociceptivos. E a resposta nociceptiva induzida pelo ácido acético é sensível tanto aos anti-inflamatórios esteroidais e não esteroidais quanto aos analgésicos opióides (DUTRA et al., 2006; FISCHER et al., 2008). A dipirona é um dos principais analgésicos utilizados pela terapêutica brasileira. Possui ação analgésica e antitérmica por agir sobre a cascata do ácido araquidônico inibindo a síntese de prostaglandinas e oxido nítrico, que reduz as citocinas proinflamatórias. A dipirona age também no bloqueio das cicloxigenases (COX), interfere sinergicamente em nível central com peptídeos analgésicos e serotonina, e inibe o glutamato, promovendo analgesia multimodal (VALE, 2006).

As preparações com própolis, tanto proveniente do CCA como do Laboratório Apis Flora, apresentaram percentuais de inibição do estímulo nociceptivo estatisticamente similares a dipirona, indicando que a própolis possui atividade antinociceptiva. As contorções foram reduzidas significativamente, em 52,43\%, 52,58\%, $67,97 \%$ e $59,34 \%$ em relação ao controle (solução hidroalcoólica), através da administração da solução de própolis nas concentrações de 10\% (Apis-Flora), $10 \%$ (CCA), 20\% (Apis-Flora) e 20\% (CCA), respectivamente (Tabela 2 ).

Tabela 2 - Percentual de inibição dolorosa induzida por injeção intraperitoneal de acido acético $0,6 \%$, em camundongos tratados com solução de própolis

\begin{tabular}{l|lc}
\hline GRUPO & TRATAMENTO & PERCENTUAL DE INIBIÇÃO \\
\hline Grupo 1 & Solução hidroalcoólica + ác. Acético 0,6\% & $0,0 \mathrm{a}$ \\
Grupo 2 & Dipirona + ác. Acético 0,6\% & $75,82 \mathrm{~b}$ \\
Grupo 3 & Solução própolis 10\% (Apis Flora) + ác. Acético 0,6\% & $52,43 \mathrm{~b}$ \\
Grupo 4 & Solução própolis 10\% (CCA) + ác. Acético 0,6\% & $52,58 \mathrm{~b}$ \\
Grupo 5 & Solução própolis 20\% (Apis Flora) + ác. Acético 0,6\% & $67,97 \mathrm{~b}$ \\
Grupo 6 & Solução própolis 20\% (CCA) + ác. Acético 0,6\% & $59,34 \mathrm{~b}$ \\
\hline DMS $=23,52$ & CV $(\%)=0,64$ & \\
\hline
\end{tabular}

Letras diferentes na mesma coluna indicam diferença significativa $(\mathrm{P}<0,05)$.

Fonte: Autores. 
Nunes et al. (2014) demonstraram que o extrato etanólico da própolis vermelha possui ação antinociceptiva central e periférica, pois promoveu redução no número de contorções abdominais induzias pelo acido acético $(0,6 \%)$, em todas as dosagens analisadas (3, 10 e $30 \mathrm{mg} /$ $\mathrm{kg}$ ), além de reduzir a ação da formalina tanto na fase neurogênica $(30 \mathrm{mg} / \mathrm{Kg})$ quanto na fase inflamatória $(3,10$ e $30 \mathrm{mg} / \mathrm{kg})$. Dulcetti Junior et al. (2004) também observaram efeito antinociceptivo do extrato hidroetanólico da própolis quando administrado em ratos, que foi capaz de inibir a resposta induzida por ácido acético além de induzir analgesia contra estímulos térmicos.

De Campos et al. (1999) comprovaram a ação analgésica do extrato etanólico de própolis brasileira através dos modelos de nocicepção induzido pelo ácido acético e zymosan. Também relataram que este extrato inibiu significativamente a dor induzida por capsaicina e reverteu a hiperalgesia induzida pela bradicinina.

A composição química da própolis pode variar de acordo com a biodiversidade da flora apícola (CASTRO et al., 2007). Portanto, a inexistência de diferença significativa entre a solução de própolis do CCA e do Laboratório Apis Flora indica que os componentes responsáveis pela inibição da sensação dolorosa são semelhantes, mesmo quando oriundos de vegetações distintas.

Entre os compostos ativos da própolis, os fenólicos, como os flavonoides, têm sido considerados substâncias biologicamente ativas, podendo justificar a sua atividade antinociceptiva. Os flavonoides são potentes inibidores da enzima oxido nítrico sintase tipo 2 responsável pela síntese do oxido nítrico (NO), além de bloquear as vias da COX e lipoxigenase (LOX), da proteína quinase $\mathrm{C}$ e L-arginina/NO (CASTRO et al., 2007; MEOTTI et al., 2006; SOUSA et al., 2009). Essas vias têm sido implicadas em uma infinidade de eventos moleculares envolvidos nas atividades anti-inflamatória e antinociceptiva de várias substâncias (SOUSA et al., 2009). Os flavonoides também são capazes de inibir a fosfolipase A2 e a fosfolipase C, enzimas importantes da cascata de mediadores dos processos inflamatórios (MIDDLETON; KANDASWAMI; THEOHARIDES, 2000).

\section{Conclusões}

A própolis em solução aquosa, preparada a partir do extrato hidroalcoólico, é capaz de inibir, em camundongos, a sensação dolorosa induzida pela injeção i.p. de ácido acético. A própolis oriunda do apiário do CCA é equivalente à industrializada pelo Laboratório Apis Flora, quanto à capacidade de inibir o estímulo doloroso induzido pelo ácido acético. As soluções de 10\% e $20 \%$, provenientes de ambas as fontes acima citadas, possuem atividade antinociceptiva similar a dipirona.

\section{Agradecimentos}

Ao Laboratório Apis-Flora, pela doação da própolis utilizada neste experimento.

\section{Referências}

BARBOSA, M. H.; ZUFFI, F. B.; MARUXO, H. B.; JORGE, L. L. R. Ação terapêutica da própolis em lesões cutâneas. Acta Paulista de Enfermagem, São Paulo, v. 22, n. 3, p. 318-322, 2009

CASTRO, M. L.; CURY, J. A.; ROSALEN, P. L.; ALENCAR, S. M.; IKEGAKI, M.; DUARTE, S.; KOO, H. Própolis do sudeste e nordeste do Brasil: Influência da sazonalidade na atividade antibacteriana e composição fenólica. Química Nova, São Paulo, v. 30, n. 7, p. 1512-1516, 2007.

CHEN, H.; ZHANG, M.; XIE, B. Components and antioxidant activity of polysaccharide conjugate froom green tea. Food Chemistry, London, v. 90, n. 1-2, p. 17-21, Mar./Apr. 2005. 
De CAMPOS, R. O.; ALVES, R. V.; FERREIRA, J.; KYLE, D. J.; CHAKRAVARTY, S.;MAVUNKEL, B. J. CALIXTO J. B. Oral antinociception and oedema inhibition produced by NPC 18884, a nonpeptidic bradykinin B2 receptor antagonist. NaunynSchmiedeberg's Archives of Pharmacology, Berlin, v. 360, n. 3, p. 278-86, 1999.

DULCETTI JUNIOR, O; ANDREUCCI, V. C.; CUNHA, I. B. da S.; ARAUJO, C. E. P.; OLIVEIRA, F. de; MARCUCCI, M. C. Investigation of the antiinflammatory and analgesic activities of a sample of Brazilian própolis. Acta Farmacêutica Bonaerense, Buenos Aires, v. 23, n. 3, p. 285-91, 2004.

DUTRA, R. C.; TAVARES, C. Z.; FERRAZ, S. O.; SOUSA, O. V.; PIMENTA, D. S. Investigação das atividades analgésica e antiinflamatória do extrato matanólico dos rizomas de Echinodorus grandiflorus. Revista Brasileira de Farmacognosia, São Paulo, v. 16, n. 4, p. 469-474, 2006.

FERNANDES JUNIOR, A.; LOPES, M. M. R.; COLOMBARI, V.; MONTEIRO, A. C. M.; VIEIRA, E. P. Atividade antimicrobiana de própolis de Apis mellifera obtidas em três regiões do Brasil. Ciência rural, v.36, n.1, p. 294-297, 2006.

FISCHER, L. G.; SANTOS, D.; SERAFIN, C.; MALHEIROS, A.; DELLE MONACHE, F.; DELLE MONACHE, G.; CECHINEL FILHO, V.; SOUZA, M. M. Further antinociceptive properties of extracts and phenolic compounds from Plinia glomerata (Myrtaceae) leaves. Biological and Pharmaceutical Bulletin, Tokyo, v. 31, n. 2, p. 235-39, 2008.

IMAGAWA, V. H. Avaliação da eficácia de três doses diferentes da dipirona sódica em cadelas submetidas à ovariosalpingohistectomia. 2006. 141 f. Tese (Doutorado em Ciências) - Universidade de São Paulo, São Paulo, 2006.

KOSTER, R.; ANDERSON, M.; BEER, E. J. Acetic acid for analgesic screening. Federation Proceedings, vol. 18, p. 412-418, 1959.

LUSTOSA, S. R.; GALINDO, A. B.; NUNES, L. C. C.; RANDAU, K. P.; ROLIM NETO, P. J. Própolis: atualizações sobre a química e a farmacologia. Revista Brasileira de Farmacognosia, São Paulo, v. 18, n. 3, p. 447-454, 2008.
MENEZES, H. Própolis: uma revisão dos recentes estudos de suas propriedades farmacológicas. Arquivos do Instituto de Biologia, São Paulo, v. 72, n. 3, p. 405-411, 2005.

MEOTTI, F. C.; LUIZ, A. P.; PIZZOLATTI, M. G.; KASSUYA, C. A. L.; CALIXTO, J. B.; SANTOS, A. R. S. Analysis of the antinociceptive effect of the flavonoid myricitrin: evidence for a role of the L-arginine-nitric oxide and protein kinase C pathways. Journal of Pharmacology and Experimental Therapeutics, v. 316, n. 2, p. 789- 796, 2006.

MIDDLETON, E. J.; KANDASWAMI, C.; THEOHARIDES, T. C. The effects of plant flavonoids on mammalian cells: implications for inflammation, heart disease, and cancer. Pharmacological Reviews, Baltimore, v. 52, n. 4, p. 673-751, 2000.

NUNES, M. S. A.; CAVENDISH, R. L.; ALBUQUERQUE Jr, R. L. C. de; CARDOSO, J. C.; GOMES, M. Z.; THOMAZZI, S. M.; SANTOS, J. de S. Atividade antinociceptiva do extrato hidroetanólico de própolis vermelha. In: SEMANA DE PESQUISA "CIÊNCIA E TECNOLOGIA PARA UM BRASIL SEM FRONTEIRAS”, 16., 2014, Tiradentes. Anais... Tiradentes: UNIT, 2014.

OLIVEIRA, R. B.; COSTA, E. A.; VALADARES, M. C.; CUNHA, L. C. da. Avaliação das atividades antiinflamatória e analgésica de extrato de Synadenium umbellatum. Revista Eletrônica de Farmácia, Goiânia, v. 2, n. 2, p. 137-139, 2005.

PASSOS, C. S.; ARBO, M. D.; RATES, S. M. K.; VON POSER, G. L. Terpenóides com atividade sobre o Sistema Nervoso Central (SNC). Brazilian Journal of Pharmacognosy, São Paulo, v. 19, n. 1, p. 140-149, 2009.

SILVA, M. S. S.; CITÓ, A. M. G. L.; CHAVES, M. H.; LOPES, J. A. D. Triterpenóides tipo cicloartano de própolis de Teresina - PI. Química Nova, São Paulo, v. 28, n. 5, p. 801-804, 2005.

SIMÕES, C. M. O. S., E. P.; SCHENKEL, E. P.; GOSMANN, G.; MELLO, J. C. P.; MENTZ, L. A.; PETRVICK, P. R. Farmacognosia: da planta ao medicamento. 6. ed. Porto Alegre: UFRGR; Florianópolis: Ed. UFSC, 2007. 
SOUSA, O. V.; FIORAVANTE, I. A.; DELVECHIO-VIEIRA, G.; CANESCHI, C. A. Investigação da atividade antinociceptiva e antiedematogênica do extrato etanólico das folhas de Joannesia princeps Vellozo. Revista de Ciências Farmacêuticas Básica e Aplicada, Araraquara, v. 30, n. 1, p. 91-97, 2009.

SUDO, R. T.; BONFÁ, L.; TRACHEZ, M. M.; DEBOM, R.; RIZZI, M. D.; ZAPATA-SUDO, G. Caracterização anestésica da nanoemulsão não lipídica de propofol. Revista Brasileira de Anestesiologia, Rio de Janeiro, v. 60, p. 475-483, 2010.

TRUSHEVA, B.; POPOLVA, M., BANKOVA, V., SIMOVA, S., MARCUCCI, M.C., MIORIN, P.L., PASIN, F.R., TSVETKOVA, I. Bioactive constituents of Brazilian red própolis. Evidence based complementary and alternative medicine: $e$ CAM 3, Oxford, v. 3, n. 2, p. 249-254, 2006.

VALE, N. Desmistificando o uso da dipirona. In: CAVALCANTI, I. L.; CANTINHO, F. A. F.; ASSAD, A. Medicina perioperatória. Rio de Janeiro: Sociedade de Anestesiologia do Estado do Rio de Janeiro, 2006. Cap. 126, p. 1107-1123. 
